\title{
QUE OPÇÕES PARA UMA POLÍTICA CULTURAL TRANSFORMADORA?
}

\author{
Rui Matoso \\ Universidade Lusófona de Humanidades e Tecnologias, Portugal
}

\begin{abstract}
Resumo: A questão fundamental é entender que cultura e cidade são interdependentes e constituintes do ecossistema urbano-simbólico, que poder e cultura são duas dimensões axiais da interação social e da resiliência cultural, e que neste contexto emerge a necessidade de abrir as diversas esferas públicas das cidades à democracia radical e ao questionamento dos problemas concretos e das potenciais soluções alternativas. Tal necessidade advém do simples reconhecimento que sem uma transformação do poder local, sem uma redefinição das estruturas de relação de poder existentes, e do seu corolário como efetiva distribuição relacional do poder pelos cidadãos, o espaço público continuará refém da inércia reprodutora dos mesmos vícios e negligências. Em suma, qualquer política cultural que se pretenda assumir como transformadora, terá de permitir no seu interior cristalizado a existência de "práticas instituintes", práticas que possibilitem a re-instituição das instituições socioculturais, que coloquem em causa a construção social do consenso operacional e favoreçam o reconhecimento das diferentes necessidades culturais e das exigências feitas por pessoas e organizações de um dado território.
\end{abstract}

Palavras-chave: Política; Cultura; Transformação.

\section{O. PREÂMBULO}

Na nossa atualidade pós-política, em que o discurso dominante tenta obstruir a própria possibilidade de uma alternativa à ordem atual, todas as práticas que possam contribuir para a subversão e a desestabilização do consenso neoliberal hegemónico são bem-vindas.

Chantal Mouffe

Com efeito, nada nos permite afirmar que de repente as políticas sociais se teriam tornado impossíveis, que as políticas industriais apenas teriam efeitos negativos, que a tecnologia estaria ao serviço exclusivo de interesses financeiros dominantes, que a ruína das antigas formas de gestão administrativa da economia apenas poderia levar ao triunfo de mercados selvagens. 
Este artigo surge na sequência da participação do autor, enquanto moderador e relator do ciclo de conferências Cultura, Espaço Público e Desenvolvimento: Que opções para uma política cultural transformadora ${ }^{1}$ promovido pela Comunidade Intermunicipal do Alentejo Central (CIMAC), nos dias 12, 13 e 14 de Junho de 2014 em Évora, uma iniciativa integrada no projecto $3{ }_{3} 4$ Incubators - Culture, Creative and Clusters for Incubators $^{2}$, de cooperação territorial europeia, financiado pelo Programa MED ${ }^{3}$, o qual tem como objetivo central a promoção do sector cultural e criativo enquanto fator de desenvolvimento territorial e de inovação económica e social.

Os comentários e sínteses das intervenções dos quatro painéis constituintes do ciclo de conferências (cultura e desenvolvimento; cultura e espaço público; cultura e território; experiências de intervenção cultural), encontram-se incluídos na publicação bilingue disponível na sua versão digital (Comunidade Intermunicipal do Alentejo Central e Matoso, 2014).

Pretende-se agora proceder a uma (meta)reflexão, distanciada do evento e da respetiva publicação, com o intuito de identificar horizontes de pensamento, investigação e ação suscitados pela pergunta inerente ao ciclo de conferências: Que opções para uma política cultural transformadora?

Resumidamente, diríamos que se trata de um conjunto de reflexões em torno das políticas culturais locais e da sua íntima conexão com a ideia premente de redemocratização da vida coletiva.

\section{ENQUADRAMENTO NO PROGRAMA MED}

Conforme referido pela organização, o ciclo de conferências "pretende abordar e debater as relações entre cultura, espaço público e desenvolvimento, procurando identificar alternativas de intervenção cultural geradoras de desenvolvimento social” (Comunidade Intermunicipal do Alentejo Central e Matoso, 2014: 5). Deste modo, a CIMAC, na sua qualidade de chefe de fila do referido projecto financiado pelo Programa MED - de Cooperação Territorial para o Mediterrâneo 2017-2013, no eixo prioritário 1: inovação, pretendeu igualmente fazer uso do principio de subsidiaridade previsto nos tratados da União Europeia, o qual implica que as decisões da União Europeia devem ser tomadas ao nível o mais próximo possível do cidadão.

Consequentemente, e segundo a entidade líder do projeto, "é necessário tirar partido da experiência e dos dados entretanto adquiridos, afinando as prioridades e as novas

${ }^{1} \underline{\mathrm{http}}: / /$ tinyurl.com.pcrqaek

2 http://www.3c4incubators.eu

3 http://www.programmemed.eu 
linhas de orientação e comunicando o sentido das realidades locais, com vista a uma "universalização" dos valores em presença, tendendo a melhorar a caracterização futura dos chamados programas de cooperação territorial europeia" (Comunidade Intermunicipal do Alentejo Central e Matoso, 2014: 5).

Com o intuito de incentivar os agentes culturais da região a adotar uma perspetiva integradora da dimensão cultural no paradigma de desenvolvimento integrado e duradouro, a organização complementou o aludido ciclo de conferências com a realização de um workshop relativo ao tema "cultura e desenvolvimento sustentável”, complementado ainda com uma série de visitas de estudo a espaços e a estruturas de produção cultural localizadas em Évora.

Dito de forma sumária, o conjunto global das iniciativas agregadas ao projecto $3 C 4$ Incubators - Culture, Creative and Clusters for Incubators, inclui-se na finalidade de promoção da coesão territorial defendida pela política regional da União Europeia (Inforegio) ${ }^{5}$, visando assim apoiar a criação de emprego, a competitividade, o crescimento económico, uma melhor qualidade de vida e o desenvolvimento sustentável.

Do ponto de vista político importava contribuir, através do princípio de subsidiaridade, para a caracterização dos futuros programas de cooperação transnacional, chamandose a atenção para a necessidade da reflexão crítica em torno das políticas públicas de cultura ao nível local, numa visão integradora da cultura nas restantes dimensões da democracia (território, espaço público, participação, educação, desenvolvimento sustentável, ...).

Do ponto de vista da participação, da capacitação e empoderamento dos agentes culturais havia que proporcionar um encontro (ciclo de conferências e workshop) que promovesse a partilha e o debate em torno das relações entre cultura, território, desenvolvimento, espaço público e as respetivas experiências de intervenção cultural.

O resultado da interlocução foi posteriormente publicado e entregue à entidade gestora do programa MED, de modo a que as necessidades e aspirações dos agentes culturais locais sejam escutadas pelos gestores dos programas de financiamento europeus (bottom-up).

Cumpre-se assim o requerimento da "existência de instituições políticas e culturais que protejam e promovam o direito à narração e, complementarmente o direito a ser

4 http://tinyurl.com/mcjapzs (consultado em 03 de novembro de 2014)

$5 \underline{\mathrm{http}: / / \text { ec.europa.eu/regional policy/index pt.cfm }}$ 
ouvido" (Bhabha, 2007: 25), bem como o entendimento da cultura como capacitação para exprimir as aspirações dos cidadãos diretamente envolvidos nas esferas da criação e produção cultural, isto é, favorecendo uma política de reconhecimento. Pois qualquer projeto ou iniciativa de desenvolvimento, seja grande ou modesta no seu âmbito, deve desenvolver um conjunto de ferramentas para identificar o mapa cultural das aspirações (Appadurai, 2004).

\section{CULTURA E DESENVOLVIMENTO}

Quando um sistema é incapaz de tratar os seus problemas vitais, se degrada ou se desintegra ou então é capaz de suscitar um meta-sistema capaz de lidar com seus problemas: ele se metamorfoseia.

Edgar Morin

No contexto da história contemporânea, a relação entre cultura e desenvolvimento económico esteve durante séculos marcada pela opressão colonial, mas foi com os processos de produção do capitalismo fordista que surgiu o termo reajustamento cultural no planeamento do desenvolvimento económico, o qual se referia à necessidade de promover um processo de sujeição social e de aculturação das populações autóctones, pois em diversos países colonizados as suas tradições culturais dificultavam a expansão do trabalho industrial em massa.

Rodolfo Stavenhagen (2001) foi mais longe ao definir o conceito de "colonialismo interno" para se referir à condição dos povos nos países colonizados e a sua subjugação a uma política que os induzia a incorporar a cultura da economia capitalista nas suas próprias vidas, significando muitas das vezes a destruição das suas representações e produções culturais.

Na década de 1970, a noção de "etnodesenvolvimento" (Stavenhagen, 2001) surgiu como meio de combater o etnocídio, permitindo uma resposta dos grupos étnicos e minorias e o reencontro com os valores da sua cultura específica, com foco no reforço da sua capacidade de resistir à exploração e opressão e, especialmente, no seu poder de decisão independente, através de um controlo mais eficaz dos processos políticos, económicos, sociais e culturais que afetam o seu desenvolvimento. A cultura do apartheid na África do Sul é um exemplo clássico de como a imposição da segregação étnica serviu os interesses exclusivos de desenvolvimento económico da classe dominante. Neste contexto só a mundivisão pós-colonial de personalidades como Frantz Fannon, Leopold Senghor, Aimé Cesaire ou Amilcar Cabral, permitiu identificar 
a urgência da descolonização cultural como fundamental para a luta pela libertação nacional.

A UNESCO viria a enfatizar pela primeira vez em 1982 a relação entre cultura e desenvolvimento na conferência mundial sobre políticas culturais (Mondiacult). Na declaração do México (UNESCO, 1982), foi redigido um capítulo exclusivamente dedicado à dimensão cultural do desenvolvimento:

\section{DIMENSÃO CULTURAL DO DESENVOLVIMENTO}

10. A cultura é uma parte essencial do processo de desenvolvimento e ajuda a reforçar a independência, a soberania e a identidade das nações. O crescimento tem sido frequentemente concebido em termos quantitativos, sem levar em conta sua dimensão qualitativa necessário, ou seja, a satisfação das aspirações espirituais e culturais do homem. O desenvolvimento autêntico persegue o bem-estar e satisfação contínua de todos e cada um.

11. É essencial humanizar o desenvolvimento; seu objetivo final é a dignidade individual da pessoa e responsabilidade social. O desenvolvimento envolve a capacidade de cada indivíduo e cada povo a aprender, aprender e compartilhar as suas experiências.

12. Proporcionar a todos os seres humanos a oportunidade de construir um futuro melhor pressupõem que deve ser ajustado continuamente o ritmo de desenvolvimento.

13. Um número crescente de mulheres e homens querem um mundo melhor. Não só buscar a satisfação das necessidades básicas, mas o desenvolvimento do ser humano, seu bem-estar e sua possibilidade de convivência harmoniosa com todos os povos. Seu objetivo não é a produção, o lucro ou o consumo em si, mas a sua plena realização individual e coletiva, e da preservação da natureza.

14. A humanidade é o que está nos princípios e nas finalidades do desenvolvimento.

15. Qualquer política cultural deve resgatar o sentido profundo e o desenvolvimento humano. Novos modelos são necessários e é no campo da cultura e da educação que eles têm de procurar-se.

16. Só podemos assegurar um desenvolvimento equilibrado através da integração de fatores culturais nas estratégias para alcançá-lo; consequentemente, estas estratégias devem sempre levar em conta o contexto histórico, social e cultural de cada sociedade. 
De 1970 até ao presente foi constante o embate entre perspetivas distintas, por exemplo entre o Choque de Civilizações de Samuel Huntington (1999) e o Orientalismo de Edward Said (2004). Todavia, neste campo, o papel da UNESCO e do Programa das Nações Unidas para o Desenvolvimento (PNUD) tem sido relevante na defesa da importância da dimensão cultural do desenvolvimento. O relatório de 1995, Our Creative Diversity (UNESCO,1995) ou o relatório de 2004 do Desenvolvimento Humano Liberdade Cultural num Mundo Diversificado (Programa das Nações Unidas para o Desenvolvimento, 2004), são exemplos claros disso mesmo.

Independentemente das conquistas políticas e culturais efetivas, é inegável que cultura e desenvolvimento se interpenetram e quase se fundem, evidenciando o composto dinâmico que Augusto Santos Silva (2000) identifica com o Ser e o Agir, duas dimensões fundamentais da existência humana que, na sua interdependência íntima, conferem sentido às diversas estratégias de ação. A cultura é, portanto, o lugar mais adequado para pensar a integração das múltiplas dimensões do desenvolvimento. Contudo, uma outra correlação indispensável quando se trata de abordar o tema do desenvolvimento é a sua conexão direta com a qualidade efetiva da democracia, designadamente quando a colocamos ao nível local, uma vez que é a esta escala que a participação democrática ativa e plural mais se faz sentir e os seus efeitos maior potencial comportam.

Se o desenvolvimento tem necessariamente a ver com transformação, por ser sobretudo um processo de elaboração, confronto e realização de projetos, torna-se necessário uma política cultural do desenvolvimento: a cultura como consciência crítica do desenvolvimento; e em simultâneo, uma política de desenvolvimento da cultura: reforço da democracia participativa e da diversidade cultural, participação culturalmente orientada.

Pressupõe-se portanto um desenvolvimento endógeno - nunca limitado a uma visão ensimesmada, mas pelo contrário, aberta ao cosmopolitismo -, para que os atores possam mudar-se a si mesmos através da criatividade social em vez de continuarem presos a imposições neocoloniais de qualquer género. E desta forma, "assegurar a cada um a possibilidade de contribuir para a formação de ideias e participar na definição das opções que determinam o futuro", diz a Declaração Europeia sobre os Objectivos Culturais (Conselho da Europa, 1984).

As possibilidades de auto-determinação e livre intervenção cívica correspondem às ideias desenvolvidas por Amartya Sen na sua obra $O$ Desenvolvimento como Liberdade, partindo do princípio fundamental de que a liberdade individual é um 
produto social que emerge da construção interativa e interdependente entre atores sociais, e da compreensão cooperante dos problemas e das soluções (Sen, 2003). Assim, a expansão das liberdades substantivas é tida como fim prioritário e como meio principal do desenvolvimento na liberdade política: possibilitar aos cidadãos a oportunidade de discutir, debater e participar nas escolhas dos princípios e valores para eleger as prioridades do desenvolvimento.

Se entendermos que a participação requer capacitação, conhecimentos e competências educacionais básicas, e que a cultura é um aspeto fundamental da capacitação, é forçoso reconhecer a urgência de políticas culturais locais inspiradas na democracia e cidadania cultural ${ }^{6}$ e nos valores do desenvolvimento humano ${ }^{7}$. Em termos pragmáticos, aplicados às realidades municipais, é isto que defende a Agenda 21 da Cultura (A21C) ${ }^{8}$, a qual vê na diversidade cultural o principal património da humanidade, e defende a inclusão da dimensão cultural como quarto pilar do desenvolvimento sustentável, pois "existem claras analogias políticas entre as questões culturais e ecológicas. Tanto a cultura como o meio ambiente são bens comuns da humanidade" (Agenda 21 da Cultura, 2004).

A Convenção sobre a Proteção e a Promoção da Diversidade das Expressões Culturais, adotada em Outubro de 2005 pela $33^{\text {a }}$ Conferencia Geral da UNESCO, e ratificada em Dezembro do mesmo ano pela União Europeia, explicita no seu Artigo $2^{0}$ (princípios orientadores) alínea 6 (princípio do desenvolvimento sustentável) que "a diversidade cultural é uma grande riqueza para os indivíduos e sociedades. A proteção, a promoção e a manutenção da diversidade cultural constituem uma condição essencial para um desenvolvimento sustentável em benefício das gerações presentes e futuras” (UNESCO, 2005).

Ao ratificar esta convenção, os Estados-membros comprometem-se a empenhar-se em integrar a cultura nas suas políticas de desenvolvimento, a todos os níveis, tendo em vista criar condições propícias ao desenvolvimento sustentável e, neste contexto, privilegiar os aspetos ligados à proteção e à promoção da diversidade das expressões

6 A noção de "cidadania cultural" denota o papel formativo da cultura na compreensão e construção das práticas de cidadania, tais como as formações de identidade e os comportamentos altruístas que contribuem para uma capacidade coletiva de viver juntos. A cidadania cultural centra-se na expressão, produção e participação cultural como processos chave através dos quais a cidadania se desenvolve e floresce.

7 "O desenvolvimento humano está preocupado com o que eu considero ser a ideia de desenvolvimento de base: ou seja, o avanço da riqueza da vida humana, mais do que a riqueza da economia em que os seres humanos vivem, que é apenas uma parte dela." Amartya Sen, PNUD. Consultar: http://hdr.undp.org/en/humandev

8 A Agenda 21 da cultura é o primeiro documento, com vocação mundial, que aposta por estabelecer as bases de um compromisso das cidades e dos governos locais para o desenvolvimento cultural. Consultar: http://www.agenda21culture.net/ 
culturais (Artigo $13^{\circ}$ - integração da cultura no desenvolvimento sustentável). Portugal ratificou a adesão à convenção em 2007, tendo entrado em vigor no dia 16 de Junho9 . A pergunta evidente é a de saber se e como os Estados-membros, designadamente Portugal, realizaram este compromisso ratificado com a UNESCO?

Até ao momento não existem evidências de que tal tenha efetivamente sido realizado, e para que tal evidência se verificasse "a todos os níveis" teria certamente de haver uma resolução política que permitisse alterar o paradigma das políticas de cultura ao nível local ${ }^{10}$.

\section{POLÍTICAS CULTURAIS TRANSFORMADORAS}

A vida urbana supõe que aconteçam encontros, confrontos e diferenças, conhecimento e reconhecimento recíprocos (em que se inclui o combate ideológico e político) dos modos de viver, patterns que coexistem na cidade.

\section{Henri Lefebvre}

De que modo as políticas públicas de cultura são transformadoras? Transformadoras de quê? De que forma as políticas culturais locais, (in)existentes atualmente em Portugal, favorecem este desiderato? Quais são os mecanismos públicos que promovem a democracia cultural participativa, por exemplo?

Antes de prosseguir, consideramos que existe uma questão de fundo que não terá sido ainda suficientemente elucidada na esfera pública cultural. A ideia hoje muito em voga de que as políticas culturais são na sua essência dirigidas à cultura objetivada, declinadas em políticas de arte, políticas de património, políticas de mercado (indústrias criativas e culturais), isto é, políticas das coisas e dos profissionais; fazendonos esquecer que o processo cultural culmina na receção individual e na interação social simbólica, ou seja, numa qualidade subjetiva da cultura, na qual reside o potencial da individuação psicológica (self) e social - a cultura não é simplesmente uma soma de atividades dispersas, mas antes o conglomerado de diversos modos de vida com sentidos distintos. Através desta ultima aceção, a cultura é tida para além das práticas profissionais e institucionais no campo das artes e do património, e é encarada como um processo criador continuo que não é apenas fruto do trabalho dos artistas ou de outros profissionais da cultura, nem sequer das instituições, mas de todos os grupos

9 Aprovada pela Resolução da Assembleia da República n. ${ }^{\circ}$ 10-A/2007; ratificada pelo Decreto do Presidente da República n⿳0 27-B/2007.

10 Vide: Insights for the future implementation of art. 13 - David Throsby http://unesdoc.unesco.org/images/o015/001572/157287E.pdf 
sociais e indivíduos. É neste sentido, que importa ter em consideração o alargamento inclusivo da base social das práticas e das políticas culturais.

É na esfera da cultura-ação "vivida, relacional, assente no incessante ofício de reinterpretação e reatualização dos significados circulantes nos processos de interação" (Lopes, 2007: 16), que a lacuna existe e persiste, no que respeita à construção de políticas culturais públicas. Todavia, as causas estão também há muito diagnosticadas.

A maior destas lacunas, e a mais estruturante, é sem dúvida a inexistência de um debate construtivo e conclusivo acerca dos modelos de políticas culturais locais motivadas pela intensificação da democracia e pelo ideário pragmático do desenvolvimento humano sustentável ${ }^{11}$, tendo em consideração que aos executivos municipais e administração pública local cabe, em grande medida, a responsabilidade de ser facilitador e regulador dos processos de mudança, nomeadamente na requalificação e adaptação dos serviços públicos de cultura.

Apesar da existência de exceções, a realidade global vem no entanto sendo outra, pois o forte intervencionismo do poder local, "legitimado, em boa parte, pela debilidade da sociedade civil ou pela exiguidade do sector privado implicado na produção e distribuição culturais, cria redes clientelares e mesmo efeitos perversos de imposição arbitrária de segmentos particulares de gosto. Não raras vezes, a política cultural da autarquia, refletindo o presidencialismo municipalista, é o reflexo pouco subtil do gosto do seu responsável máximo" (Lopes, 2000: 83).

Diversos outros estudos empíricos (Ribeiro, 2007; Ferreira, s/d; Fortuna \& Silva, 2002) sobre políticas e práticas culturais em Portugal evidenciam que o principal obstáculo à existência de políticas públicas de cultura municipais reside num poder político cujos modelos de governação são adversos à diversidade e à democracia cultural, i.e., a generalidade dos autarcas, diz Augusto Santos Silva, "tem grande dificuldade em entender, de forma não instrumental, a natureza e o alcance das manifestações que resultam destes ambientes urbanos e se concretizam em participação, interação e expressão cultural." (Silva,1995: 262). Esta postura radica ainda no então designado "grau zero do poder local"12, ou seja, num funcionamento excessivamente consensual da ação política e na sua contrapartida mais elementar: o fazer obra.

11 Sobre a relação entre cultura e desenvolvimento humano sustentável vide: https://www.academia.edu/3504522/CULTURA_E_DESENVOLVIMENTO_HUMANO_SUSTENT\% C.3\%81VEL

12 Vide: Juan mozzicafredo, Isabel Guerra, Margarida A. Fernandes, João Quintela [1988]. Revista Crítica de Ciências Sociais $n^{\circ}$ 25/26. 
Quando referimos anteriormente que a qualidade da democracia e cidadania cultural se aferem pela capacidade de assegurar a cada um a possibilidade de contribuir para a formação de ideias e participar na definição das opções que determinam o futuro, podemos concluir que estamos ainda longe desta tão simples e genuína exigência de soberania popular.

Num outro ângulo desta mesma problemática, o do direito à cidade, tal como defendido por Henri Lefebvre (2012), ou seja do direito a construir a cidade que idealizamos (democrática e inclusiva, criativa e bela, inteligível e justa,...); a situação não é melhor, pois, segundo o geógrafo e urbanista, comissário da Carta Estratégica de Lisboa ${ }^{13}$, João Seixas, uma parte considerável do poder local "se encontra aprisionado por aparelhos partidários com estratégias laterais e parcelares muitas vezes distintas das que poderiam prosseguir objectivos mais colectivos (...) Contribuindo estes factores, por sua vez, para uma paisagem sociocultural onde são manifestas as dificuldades ou mesmo o desinteresse no desenvolvimento de culturas activas de cooperação e de subsidiariedade, e a considerável distância face aos cidadãos e às suas formas de expressão cívica” (Seixas, 2013: 44-45).

As cidades ideais são entidades dinâmicas, e por isso mesmo geram novas formas de organização, novos projetos e novas relações sociais consubstanciadas em redes locais de tipologias diversas. As cidades não podem ser meras máquinas artificiais e administrativas capturadas pelos fluxos globais de hegemonização, da informação e do financiamento. Nem produtos prontos-a-consumir enclausuradas numa cultura burocrática.

A questão fundamental aqui, é entender que cultura e cidade são interdependentes e constituintes do ecossistema urbano-simbólico, e que poder (relacional e distribuído) e cultura são duas dimensões estruturais da interação social e da resiliência cultural ${ }^{14}$.

Neste ponto do diagnóstico, é simples de verificar que a ausência de determinadas circunstâncias dificulta a implicação dos cidadãos na conceção das próprias políticas, estratégias e projetos. Ausências, tais como:

13 http://www.cm-lisboa.pt/municipio/camara-municipal/carta-estrategica (consultado em o6 de novembro de 2011)

14 A resiliência cultural de uma cidade é a energia interna (vitalidade) que permite que a cidade consiga reagir a forças externas, adaptar-se criativamente a elas mas conservar a sua identidade específica, a longo prazo, apesar dos processos de transformação turbulentos. A noção de resiliência cultural enfatiza a necessidade de salvaguardar a memória cultural da comunidade enquanto força produtora e formadora da consciência coletiva, contribuindo para a sustentabilidade da confiança, da cooperação e da coordenação de ações, promovendo um sentido de pertença e de comunidade. A resiliência cultural depende da capacidade de reflexão e decisão de forma sistemática, multidimensional, aberta e relacional, vinculando as perspetivas de curto, médio e longo prazo. 
- de serviços públicos de cultura orientados para o desenvolvimento cultural duradoiro (sustentabilidade);

- de mecanismos pro-ativos de participação cívica;

- de medidas que favoreçam a diversidade cultural, os direitos e as liberdades culturais;

- de estratégias e políticas transparentes e publicadas;

- de linhas de financiamento público escrutináveis dirigidas a projectos de cidadania cultural;

- da revitalização do espaço público e da esfera pública cultural, abertos ao agonismo, à dissensão, à diversidade, à estranheza e à diferença (Lopes, 2007: 72);

- da valorização da criatividade social e do pensamento crítico;

- da promoção da diversidade semiótica da cidade;

- da capacitação do trabalho em rede e da cooperação entre atores sociais;

- da auto-limitação dos poderes do Estado (local, regional, nacional);

- da separação clara entre as funções político-administrativas e as funções estéticas (comissariados, curadorias, programações,...); da implementação de mecanismos e processos de arms lenght, que separem o poder executivo das opções estéticas (culturais, artísticas);

- da definição de mecanismos de participação da sociedade civil na gestão, programação e avaliação de equipamentos culturais públicos;

- de possibilidades de transformação das instituições socioculturais abertas à participação múltipla dos agentes culturais (práticas instituintes);

- de políticas e estratégias favoráveis à diversidade e pluralidade de minorias culturais e artísticas (iniciativas moleculares) versus a valorização e empenho político-administrativos em prol de eventos maioritários e de massas (de largo espectro eleitoral);

- a dificuldade de articulação e cooperação inter-associativa e entre protagonistas (programadores, artistas, ativistas,...) por um lado; e a tentação (real) da municipalização da cultura, ou seja, a absoluta centralidade dos equipamentos e 
dispositivos municipais e participação direta da Câmara como produtora de eventos culturais, por outro; o que na prática significa a imposição de um consensualismo sociocultural, logo um défice de práticas diversificadas e a redução dos "mundos" possíveis a uma unificação ideológica.

Neste sentido, a cultura enquanto dimensão de política pública não pode continuar a ser entendida como mero ornamento populista, entretenimento ou ocupação dos tempos livres vocacionada para a distração dos cidadãos mais aborrecidos (pão e circo). Uma política cultural democrática e atenta aos quotidianos e às circunstâncias concretas em cada momento e geografia, deve acima de tudo entender a cultura como uma capacidade ativa de cidadania: como conjunto de ferramentas simbólicas e conceptuais que os membros de uma comunidade necessitam para lidar com a realidade difusa do mundo contemporâneo e para elaborar novas estratégias de vida coletiva.

Como não existe desenvolvimento sustentável sem participação ativa e crítica dos cidadãos (de baixo-para cima), também a construção de uma política cultural local deve obrigatoriamente nascer de um debate público democrático, plural e inclusivo. $\mathrm{O}$ desenvolvimento cultural apoia-se na multiplicidade dos agentes sociais, e os princípios de boa governança incluem a transparência informativa e a participação cidadã na conceção das políticas culturais, nos processos de tomada de decisões e na avaliação de programas e projetos ${ }^{15}$.

A motivação para a mudança urgente e necessária na direção de sociedades sustentáveis e indutoras de bem-estar equitativamente distribuído não pode fazer esquecer as circunstâncias atuais da política e da microfísica do poder, a colonização tecnocrática e o controle do espaço público ou a concentração excessiva de poder nas formas de governação pública atuais.

Não existem contudo fórmulas mágicas ou saltos quânticos que permitam passar de um ambiente urbano monocromático, em especial nas cidades médias e pequenas, onde a dominação sociopolítica é exercida atavicamente pelos mesmos agentes de sempre, para a construção imediata ou espontânea da ação coletiva e da inovação social. Nem a implementação burocrática de fóruns participativos como um fim em si mesmo deve ser vista como contributo consistente para o desenvolvimento sustentável. Iniciar um processo de construção de uma política cultural local requer "planeamento estratégico criativo e participativo" e o uso consistente de metodologias que visem a mudança social e a inclusão da ação coletiva.

15 Vide Agenda 21 da Cultura - princípios, $5^{\circ}$. 
Um dos processos recentemente realizados em Portugal foi a elaboração das Estratégias para a Cultura em Lisboa, e a sua publicação num documento que regista a metodologia participativa e as fases de diagnóstico, análise e identificação de medidas e projectos. O Guía para la participación ciudadana en el desarrollo de políticas culturales locales para ciudades europeas ${ }^{16}$; Towards an architecture of governance for participatory cultural policy making e Towards Cultural Citizenship: Tools for Cultural Policy and Development, da autoria de Colin Mercer ${ }^{17}$, Cultural Governance in Sustainable Cities ${ }^{18}$, de Nancy Duxbury ou ainda The Hangzhou Declaration: Placing Culture at the Heart of Sustainable Development Policies ${ }^{19}$ são recursos úteis e pragmáticos, entre outros documentos e casos-de-estudo existentes neste âmbito e em diversas geografias ${ }^{20}$. No que concerne a metodologias participativas já testadas o documento Advice on local implementation of the Agenda 21 for culture ${ }^{21}$ é um guia eficaz para a implementação de políticas culturais locais destinado às cidades aderentes à Agenda 21 da Cultura.

O Mapeamento Cultural (Cultural Maping) como ferramenta de envolvimento dos cidadãos é crucial para a formulação de políticas participativas e para a realização da cidadania ativamente envolvida como sujeito e objeto do processo de planeamento. Recentemente o Centro de Estudos Sociais (Coimbra), realizou uma conferência internacional: Mapping Culture: Communities, Sites and Stories ${ }^{22}$, onde foi lançado o projeto Artéria: o Centro em Movimento ${ }^{23}$, o qual propõe para reflexão a forma como a atividade artística pode contribuir para refundar as bases da cidadania, da democracia e da sustentabilidade urbanas, o projeto fornece ainda uma plataforma em linha para suporte da cartografia das comunidades em causa e relevando simultaneamente aspetos tangíveis e intangíveis.

Um outro projeto de investigação, Culturizing Sustainable Cities ${ }^{24}$, pretende responder à questão: Como podem as práticas artísticas e culturais ser incorporadas no planeamento e desenvolvimento de cidades mais sustentáveis? Enquanto que o

\footnotetext{
16 http://www.ecumest.ro/pdf/Guia_participation_ciudadana_ESP_web.pdf (consultado em o6 de novembro de 2014)

17 https://www.academia.edu/786688/Towards_Cultural_Citizenship_Tools_for_Cultural_Policy_and_D evelopment (consultado em 06 de novembro de 2014)

${ }^{18}$ http://www.ces.uc.pt/myces/UserFiles/livros/1097_Duxbury2014-KultUr1\%281\%29.pdf (consultado em o6 de novembro de 2014)

${ }^{19}$ http://www.unesco.org/new/fileadmin/MULTIMEDIA/HQ/CLT/images/FinalHangzhouDeclaration201 30517.pdf (consultado em o6 de novembro de 2014)

${ }^{20}$ Neste campo, mas com uma abordagem sociológica, as obras de Isabel Carvalho Guerra são um importante contributo: Guerra, Isabel (2006) Participação e acção colectiva. Cascais: Princípia Editora; Guerra, Isabel (2002) Fundamentos e Processos de uma Sociologia da Acção. Princípia Editora.

${ }^{21} \mathrm{http}: / /$ www.agenda21culture.net/index.php/docman/agenda21/137-d2advice-on-local-implementationof-the-agenda-21-for-culture

$22 \mathrm{http://www.ces.uc.pt/eventos/mappingculture/}$

23 http://www.ces.uc.pt/projectos/arteria7/

${ }_{24}$ http://www.ces.uc.pt/projectos/culturizing/
} 
ECLETIS (European Citizens' Laboratory for Empowerment: Cities Shared) ${ }^{25}$ publicou recentemente $A$ contribution from Cultural and Creative actors to citizens' empowerment (disponível em www.ecletis.eu), onde se relatam múltiplas experiências de cidades europeias em torno do papel da cultura na revitalização plural da esfera pública.

\section{COMPLEXIDADE, TRANSDUÇÃO E TRANSGOVERNANÇA}

A capacidade transdutiva é partilhada pelo homem e pela máquina, contudo éo "vivente" que na sua dimensão problemática, geradora de devir e mediação, opera segundo um teatro de individuações e que avança de meta-estabilidade em meta-estabilidade.

\section{Gilbert Simondon}

Os processos de desenvolvimento local sustentável, enquanto sinónimo de transformação e resiliência, colocam a tónica no papel desempenhado pela governação, enquanto processo interativo e reflexivo de debate e diálogo e capacidade de gerir a crescente complexidade da cidade como evolução e sistema dinâmico em constante fluxo, de resolver conflitos gerando novas sínteses, integrando vários elementos e componentes geralmente considerado separados ou em conflito/contradição, identificando novas conexões, sinergias e redes relacionais.

A (trans)governança da cidade promove a cooperação e a capacidade de coordenar ações de múltiplos atores diferentes, a construção de uma rede neural de conexões, fornecendo à cidade uma capacidade intrínseca de auto-organização. Neste aspeto, uma ação bem sucedida é mais do que o cumprimento das metas específicas, é também sobre a criação eficaz e efetiva de uma plataforma coletiva e permanente de concertação social (Duxbury, 2014).

O conceito de transgovernança desenvolvido por Louis Meuleman observa que as estruturas de governança atualmente existentes parecem negar a complexidade social e a incerteza do nosso mundo contemporâneo e argumenta que "a governança da sustentabilidade deve ser mais culturalmente sensível, reflexiva e dinâmica" (2013: 37), o que exige atenção permanente e sistemática para traduzir ou adaptar as possíveis soluções para um determinado contexto cultural, e requer instituições, instrumentos, processos e envolvimento dos atores sociais.

Em nosso entendimento, e no contexto do urbanismo, a proposta de Meuleman surge na esteira do conceito de transdução usado por Henri Lefebvre na sua obra $O$ Direito à

${ }^{25}$ http://www.eclectis.eu/ 
Cidade, onde refere que "a transdução supõe um feedback incessante entre o quadro conceptual utilizado e as observações empíricas. A sua teoria (metodologia) dá forma a certas operações mentais espontâneas do urbanista, do arquiteto, do sociólogo, do político e do filósofo. Ela introduz o rigor na invenção e conhecimento na utopia” (2012: 111).

A pertinência do uso da ideia de transdução prende-se com a necessidade de entender a cidade enquanto suporte das mediações (relacionais e comunicacionais), i.e., de conceber a cidade como "um sistema semântico, semiótico ou semiológico, a partir da linguística, da linguagem urbana ou da realidade urbana concebida como um conjunto de signos" (idem: 65), e que implica compreender a função de modulação e tradução (transdução) da pluralidade de informação e conhecimento circulante na cidade.

No campo da filosofia da técnica e da comunicação (ressonância, individuação, iteração, interação, feedbacks múltiplos), a genealogia da hermenêutica dos processos transdutivos (entre seres humanos e os meios ambientes urbanos, naturais e tecnológicos) deve contudo ser procurada na obra do filósofo francês Gilbert Simondon (2009), o qual foi de facto quem mais desenvolveu este quadro conceptual, a partir dos pressupostos da filosofia evolucionista (Bergson e Georges Canguilhem), da etnografia e da teoria da projeção orgânica (Ernst Kapp).

A utilidade de transpor para a temática da governança urbana o quadro teórico da transdução, deve-se, tal como referido anteriormente (Meuleman), à necessidade de desenvolver novos paradigmas e modelos de governança e sustentabilidade que incluam a dimensão cultural na sua verdadeira potência (diversidade, pluralismo, democracia, participação, redes e tecnologias,...).

Importa pois reconhecer que a noção clássica de forma (estática) se tornou insuficiente para pensar a transdução, pois a teoria da forma ignora a meta-estabilidade (equilibro meta-estável); é então necessário que seja substituída pela noção de in-formação (forma significativa). Pensar transdutivamente é mediar entre ordens diferentes e colocar realidades heterogéneas em contacto, e transformando-as em algo diferente - e representa a verdadeira marcha da invenção, não sendo por isso dedutiva nem indutiva (Simondon, 2009). Um evento transdutivo é então aquele que articula realidades diferentes, fazendo emergir o que antes existia separadamente.

É para nós evidente que quando hoje se equacionam as problemáticas de governança, sustentabilidade e políticas públicas de cultura, temos de ter em mente a complexa meta-estabilidade (permanente tensão equilíbrio-desequilíbrio) associada ao desenvolvimento e uso das novas tecnologias, designadamente sabendo de antemão 
que a essência das tecnologias transdutivas reside na mediação das relações entre pessoas, máquinas, coisas e animais. É preciso pois notar que a mediação técnica não liga diretamente, mas modula as relações dos coletivos sociotécnicos (homemmáquina). Uma das linhas de pesquisa nesta área da organologia é a desenvolvida por Bernard Stiegler, e por si designada como "psicotecnologias da transindividuação" (Stiegler e Rogoff, 2010), e vem sendo aplicada no centro de investigação coordenado por Stiegler e Vincent Puig no Centre Pompidou².

Com maior ou menor ênfase no papel das tecnologias no quotidiano das cidades, no espaço público ou espaço privado, na gestão do bem comum ou na individuação psicológica e social, o que não podemos negar é que as estratégias políticas de governança requerem o pensamento complexo para lidar com o "incerto, o acaso, o jogo múltiplos das retroacções” (Morin, 1991: 19). Estas transformações de paradigmas pressupõem uma viragem do pensamento (mindset), do pensamento simples (disjuntivo e segregador) para o complexo (multidimensional, integrador) capaz de ultrapassar as dificuldades contemporâneas reproduzidas pela "patologia do saber" e pela "inteligência cega" (idem: 16).

\section{CODA}

Em Notas para una ética hacker en la cultura local, José Ramón Insa Alba (s/d), realiza uma justa síntese da convergência da cultura tecnológica nas realidades culturais institucionais, afirmando mesmo que "a capacidade de recombinar informação e conhecimento através das estruturas sociais é a verdadeira fonte de inovação para a cultura local”, o contexto é tudo e não pode haver nenhum progresso real sem uma interação aberta.

Ao nível das instituições, contínua José Alba, o “autismo produz monstros”, pois não há nenhuma maneira de continuar a trabalhar a partir de modelos institucionais herdados do séc. XIX. Assim, o trabalho atual das instituições públicas deveria ser o de laboratório, ou seja, mais do que a mera distribuição de programas culturais, ligeiramente idênticos em todo o lado. É simples: Imagine-se as instituições públicas locais como espaços para a troca e debate de ideias. É simples, mas raramente acontece.

Para além da crítica dos modelos ultrapassados de governança urbana, importa igualmente a escala crítica das instituições públicas, mas também a esse nível nos confrontamos com a hipótese, levantada por Chantal Mouffe (2014), resultante da sua

${ }^{26} \underline{\mathrm{http}}$ ///www.iri.centrepompidou.fr/ 
participação no Truth is Concrete ${ }^{27}$, de que a produção simbólica é agora um objetivo central do capitalismo e, por meio do desenvolvimento das indústrias criativas, as pessoas tornaram-se totalmente subjugadas ao controle do capital? Sendo assim,devem as práticas artísticas críticas estar envolvidas com as atuais instituições, com o objetivo de transformá-las ou devem abandoná-las por completo?

De acordo com Chantal Mouffe a primeira hipótese é a mais pertinente, pois as práticas artísticas críticas são aquelas que, de várias maneiras, desempenham um papel no processo de desarticulação/rearticulação que caracteriza a política contra-hegemónica, que assim pretende atingir as instituições que incorporam a hegemonia dominante, a fim de provocar transformações profundas na forma como elas funcionam. O domínio da cultura desempenha pois um papel crucial nesta guerra de posição, porque este é um dos terrenos onde o senso comum e as subjetividades são construídos.

Existe uma grande variedade de formas possíveis para fazer emergir espaços agonísticos, defende Mouffe, espaços onde o consenso dominante possa ser desafiado e que podem surgir dentro e fora das instituições. De facto, ainda que esta seja uma ideia constantemente referida pela filósofa francesa, a existência do agonismo público (debate entre projetos alternativos e visões distintas) é de particular interesse quando nos situamos no lugar perigoso que é o encontro entre política (poder) e a organização social e estética do consenso (controlo).

É sabido, desde Kant (1998) e da sua Crítica da Faculdade do Juízo, que o prazer estético não se define tanto como o que o sujeito experimenta em relação ao objeto, mas como prazer que deriva de constatar a própria pertença a um grupo consensual de apreciadores desse mesmo objeto e da sua capacidade para apreciar o belo. Formandose assim uma esfera pública do consenso, dos gostos e do sentir em comum. Ora, é sobre esta esfera pública que agem as instituições, os poderes e as máquinas de estetização mediática, na tentativa de conservar o gosto das massas e assim manter $a d$ aeternum o consenso social, cultural e político.

A necessidade de abrir brechas nas diversas esferas públicas das cidades, aberturas à democracia radical (de raiz) e ao questionamento dos problemas concretos e das potenciais soluções alternativas, advém do simples reconhecimento que sem uma transformação do poder local, sem uma redefinição das estruturas de relação de poder existentes, e do seu corolário como efetiva distribuição relacional do poder pelos

27 Um acampamento e maratona 24/7 decorrido em Graz, entre 21/o9 e 28/09/2012, em torno de estratégias artísticas na política e estratégias políticas na arte. 
cidadãos e movimentos sociais, o espaço político continuará refém da inércia reprodutora dos mesmos vícios e negligências (laissez faire).

Em suma, qualquer política cultural que se pretenda assumir como transformadora, terá de permitir no seu interior institucionalizado a existência de "práticas instituintes" (Transform, 2008), práticas que possibilitem a re-instituição das instituições socioculturais, que coloquem em causa o falso consenso previamente existente (consenso operacional) e favoreçam o reconhecimento das diferentes necessidades culturais e das exigências feitas por pessoas e organizações de um território, incluindo os agentes culturais e todos os cidadãos.

\section{Referências bibliográficas}

Agenda 21 da Cultura (2004) Agenda 21 da Cultura. http://www.agenda21culture.net/index.php/es/docman/agenda21/9-ag21cptpdf (Consultado em o9 de novembro de 2014).

Alba, José (s/d) Notas para una ética hacker en la cultura local. http://www.academia.edu/9215684/Notas para una \%C3\%Agtica hacker en la c ultura local (Consultado em o9 de novembro de 2014).

Appadurai, Arjun (2004) "The Capacity to Aspire:Culture and the Terms of Recognition", in RAO, Vijayendra \& WALTON, Michael (eds) Culture and Public Action. California. Stanford University Press. pp. 59-85.

Bhabha, Homi K. (2007) "Ética e Estética do Globalismo: Uma Perspectiva PósColonial”, in AA.VV A urgência da Teoria. Lisboa. Fundação Calouste Gulbenkian e Edições Tinta da China. pp. 21-44.

Comunidade Intermunicipal do Alentejo Central e Matoso, Rui (2014) Ciclo de Conferências “Cultura, Espaço Público e Desenvolvimento - Que opões para uma política cultural transformadora”. Évora. CIMAC (Comunidade Intermunicipal do Alentejo Central) e Grupo Pro-Évora/Colectivo Campo Aberto. (http://tinyurl.com/mnyhqdx)

Conselho da Europa (1984). Declaração Europeia sobre os Objetivos Culturais. Estrasburgo. 
Duxbury, Nancy (2014) “Cultural Governance in Sustainable Cities”. Àgora, vol. 1, no ${ }^{0}$, pp. 165-182. $\quad$ http://www.ces.uc.pt/myces/UserFiles/livros/1097 Duxbury2014KultUr1\%281\%29.pdf (Consultado em o9 de novembro de 2014).

Ferreira, José Maria Cabral (s/d). O Pelouro da Cultura nas Câmaras da Região do Norte-Oito notas conclusivas dum inquérito por questionário. [Versão electrónica] disponível em www.ine.pt (Consultado em 15 de Julho de 2008).

Fortuna, Carlos \& Silva, Augusto (orgs.) (2002) Projecto e circunstância - culturas urbanas em Portugal. Porto. Edições Afrontamento.

Huntington, Samuel P. (1999) O Choque das Civilizações. Lisboa. Gradiva.

Kant, Imannuel (1998 [1790]) Crítica da Faculdade do Juízo. Lisboa. INCM Imprensa Nacional Casa da Moeda.

Lefebvre, Henri (2012) O Direito à Cidade. Lisboa. Letra Livre.

Lopes, João Teixeira (2000) "EM BUSCA DE UM LUGAR NO MAPA- Reflexões sobre políticas culturais em cidades de pequena dimensão". Sociologia, Problemas $e$ Práticas, n. ${ }^{\circ}$ 34, 2000, pp. 81-116.

Lopes, João Teixeira (2007) Da democratização à democracia cultural - uma reflexão sobre políticas culturais e espaço publico. Porto. Profedições.

Meuleman, Louis (2013) Transgovernance: Advancing Sustainability Governance. Springer.

Morin, Edgar (1991) Introdução ao pensamento complexo. Lisboa. Instituto Piaget.

Mozzicafredo, Juan; Guerra, Isabel; Fernandes, Margarida A. \& Quintela, João (1988) "Poder Autárquico e Desenvolvimento Local". Revista Crítica de Ciências Sociais, no 25/26. Coimbra: CES.

Mouffe, Chantal (2014) Estratégias de política radical e resistência estética [tradução do autor]. http://tinyurl.com/m8ax8ca (consultado em o8 de novembro de 2014).

Programa das Nações Unidas para o Desenvolvimento (2004) Desenvolvimento Humano Liberdade Cultural num Mundo Diversificado. http://www.pnud.org.br/HDR/arquivos/RDHglobais/hdr2004-portuguese.pdf (consultado em 03 de novembro de 2014). 
Ribeiro, Arnaldo (2007) Governança Municipal. Cidadania e Governação nas Câmaras Municipais Portuguesas. Viana do Castelo. CER-Centro de Estudos Regionais.

Said, Edward W. (2004) Orientalismo. Lisboa. Cotovia.

Seixas, João (2013) A Cidade na Encruzilhada, Repensar a Cidade e a sua Política. Porto. Edições Afrontamento.

Sen, Amartya (2003) O Desenvolvimento como Liberdade. Lisboa. Gradiva.

Silva, Augusto Santos (1995) "Políticas culturais municipais e animação do espaço urbano: uma análise de seis cidades portuguesas”, in Santos, Maria de Lourdes Lima dos (org.) Cultura \& Economia. Lisboa. ICS.

Silva, Augusto Santos (2000) Cultura e Desenvolvimento: Estudos sobre a Relação entre Ser e Agir. Oeiras. Celta Editora.

Simondon, Gilbert (2009) La individuación a la luz de las nociones de forma y de información. Buenos Aires: La Cebra Ediciones y Editorial Cactus.

Stavenhagen, Rodolfo (2001) La cuestion étnica. Mexico. Colegio de México.

Stiegler, Bernard e Rogoff, Irit (2010) "Transindividuation". Eflux Journal, n. 14. http://www.e-flux.com/journal/transindividuation/ (consultado em 03 de novembro de 2014).

Transform (2008) Producción cultural y práticas instituyentes - líneas de ruptura en la crítica instuticional. Madrid. Traficantes de Sueños.

UNESCO (1982) Mondiacult - declaração do México sobre políticas culturais. http://portal.unesco.org/culture/en/files/12762/11295421661mexico en.pdf/mexico en.pdf (consultado em 03 de novembro de 2014).

UNESCO (1995) Our creative diversity: report of the World Commission on Culture and Development. http://unesdoc.unesco.org/images/o010/001055/105586e.pdf (consultado em 03 de novembro de 2014)

UNESCO (2005) Convenção sobre a Proteção e a Promoção da Diversidade das Expressões

Culturais. http://unesdoc.unesco.org/images/0015/001502/150224por.pdf (consultado em 03 de novembro de 2014). 
Rui Matoso é gestor e programador cultural. Professor na Universidade Lusófona (ECATI), na licenciatura em Ciências da Comunicação e da Cultura e no mestrado em Programação e Gestão Cultural. É membro da European Expert Network on Culture e formador certificado pelo IEFP e pelo CCPFC. No âmbito das políticas culturais municipais vem defendo em Portugal a implementação da Agenda 21 da Cultura. É mestre em Práticas Culturais para Municípios - FCSH, Universidade Nova de Lisboa (2008), tendo anteriormente realizado uma Pós-Graduação em Gestão Cultural (2006). Atualmente desenvolve investigação sobre Arte Crítica no doutoramento em Ciências da Comunicação, e é consultor da Artemrede para o Plano Estratégico 2015-2020. rui.matoso@gmail.com 